\title{
Anomalia sexual num Nemátode marinho
}

\author{
POR \\ Marta Vannucci Mendes \\ (Interna voluntária) \\ (Com I estampa)
}

Em material marinho, colecionado em 1936 pelo Prof. P. Sawaya no litoral do Rio de Janeiro e fixado em alcool $80 \%$, o Prof. E. Marcus e Exma. Sra. Dna. E. du Bois-Reymond Marcus encontraram uma fêmea do gênero Enoplus Dujardin (1845, p. 233), com forte anomalia sexual, que me foi confiada para estudo pormenorizado.

Além do indivíduo anormal constavam do material coletado outros 5 da mesma espécie, 2 fêmeas e 3 machos, cuja sexualidade está normalmente estabelecida. A região post-anal do macho e da fêmea não apresentam diferênças. Alguns animais foram corados pelo carmin e diafanizados em óleo de cravo, outros fechados em glicerina.

\section{Discussão sistemática}

Pelas tabelas de Schuurmans Stekhoven $(1935$, p. 2-4,26) e de Schneider (1939, p. 14-27) considero como certa a classificação genérica. Como ambas as resenhas apenas abrangem as duas espécies do Mar do Norte e do Mar Báltico, não podem servir para a determinação definitiva do material presente. Fica, porém, excluida a possibilidade de se tratar de E. brevis Bast. por possuir manchas pigmentadas concentradas e não difusas, ao passo que os espécimes presentes concordam, em vários caracteres com $E$. com $\mathrm{m} u \mathrm{n}$ is Bast. As estruturas e as medidas que permitiriam classificar os espécimes atuais como E. communis são as seguintes: (Fig. I) os três termos da fórmula geralmente usada para a definição dos Nemátodes cabem nos limites apresentados por Stekhoven. Assim o primeiro, alpha $(\alpha)$, que representa a relação entre o comprimento total e a largura, deu 33 para os machos e 25-32 para as fêmeas; o segundo, beta $(\beta)_{i}$ que representa a relação entre o comprimento total e o do esôfago, deu 6-7 para os machos e 
6 para as fêmeas; o terceiro, gama $(\gamma)$, que indica a relação entre o comprimento total e.o da cauda, deu 15 para os machos e 16-17 para as fêmeas. V. i. é, a distância, em relação ao comprimento total do corpo, entre o limite anterior e a vulva, deu 57. Os animais são estreitados no bordo anterior e tão largos, ou quasi, na cárdia como no meio do corpo. Existem 3 lábios cada um com duas papilas e 10 cerdas cefálicas. A altura da cabeça até a implantação das cerdas cefálicas corresponde a um terço da linha de sutura. As mandíbulas são $44 \%$ da linha de sutura (Stekhoven dá o valor de $40 \%$ ). O póro excretor é situado no meio, ou pouco anteriormente, do comprimento do esôfago. Os espículos são encurvados e seu aspeto corresponde a uma figura de J. G. de Man copiada por Stekhoven (1935, f. 97 D). O comprimento dos espículos é de 1,7 vezes a largura anal; êles são quasi 6 vezes mais compridos que largos. $O$ aparelho copulador auxiliar parece-se ao figurado por Stekhoven $(1935$, f. 97 C). Numerosos pares de cerdas encontram-se entre a cloaca e o aparelho auxiliar, mas não me foi possivel contar exatamente o seu número. Dos dois pares de cerdas posteriores à cloaca, mencionados por Stekhoven, existe um com certeza e talvez o segundo. Ocorrem algumas cerdas escassas na cauda, cuja forma é cônica. Como o material já tinha sido manipulado anteriormente, não pude maıs verificar as chanfraduras nos espículos, nem contar exałamente as cerdas, sobretudo aquelas atraz das manchas pigmentadas e as "das linhas submedianas.

Os caracteres seguintes obstam, ao meu ver, a uma reunião dos verınes presentes a E. communis: o tamanho dos espécimes é a metade daquele indicado por Stekhoven como limite inferior da variabilidade individual; minhas medidas deram 2,1-2,3 mm. para os machos e 2,9-3,1 mm. para as fêmeas. A comparação da figura $97 \mathrm{C}$ de Stekhoven è a. Fig. 2, revela distância maior entre a terminação ental dos espículos e o nivel do aparelho copulador accessório na figura de Stekhoven. O material mediterrâneo de Marion (1870, p. 22) descrito como Énoplostoma hirtum, hoje Enoplus hirtus, (Marion) (Micoletzky, 1924 p. 236; Coninck \& Stekhoven 1933, p. 32) aproxima-se, quanto à distância entre os espículos e o aparelho copulador auxiliar, mais aos meus espécimes do que E. communis. Por outro lado, não posso identificar o material presente com E. hirtus, pois é espécie de $5 \mathrm{~mm}$ de comprimento total. Marion (1870, p. 23) descreveu tambêm um Enoplostoma minus, hoje Enoplus minor (Marion) (Coninck \& Stekhoven 1933, p. 33) do comprimento total de $2,3 \mathrm{~mm}$ com cauda de $0,21 \mathrm{~mm}$ e largura de $0,107 \mathrm{~mm}$. Como se vê - comprimento total é próximo ao dos meus exemplares; calculando porém, a relação dessas medidas obtêm-se para alpha e para gama valores que não coincidem com as medidas do meu material, apesar de não serem muito 
afastadas. Penso, por isso, não ser possivel identificar o meu material como E. $m$ inor. As manchas pigmentadas distam do bordo anterior meia largura ou menos ainda, e não, como em E. communis, uma largura inteira. As mandíbulas são 4,2 vezes tal largura, ao passo que Stekhoven da um comprimento 3,3 vezes maior. 'E' verdade que em material belga foi relatada como longura da cauda de um macho, 2,4 vezes a largura anal (Coninck \& Stekhoven 1933, p. 37), mas, tal medida não foi repetida na última resenha (1935) de Stekhoven.

Certos caracteres são inconstantes nos vários indivíduos do material presente: a largura anal que, nos machos, segundo Stekhoven, seria igual a $1 / 2$ a largura do corpo, é, num indivíduo atual 0,7 tal largura, enquanto que nos outros corresponde à diagnose de E. comm un is. A linha posterior da cápsula cefálica apresenta-se em um dos meus exemplares quasi reta. em outro ligeiramente ondulada, como na figura 35a de Bütschli (1874), e no indivíduo desenhado (Fig. I) é bastante ondulada.

Os caracteres morfológicos impossibilitam, ao meu ver, a classificação dos exemplares do Rio de Janeiro como E. com m un is, identificação que nem mesmo teria sido favorecida zoogeograficamente. Em 1933 E. communis foi, é verdade, chamado de espécie "cosmopolita" (Coninck \& Stekhoven, 1933 p. 37), mas, na última sinopse assinala esse último autor (1935 p. 27-28) apenas os mares aflânticos, árticos e boreais, com o limite meridional no canal da Mancha (Falmouth). Já de Man deixou de confirmar a ocorrência de E. commun is no Mediterrañeo (1878, p. 89).

Tendo descrito Steiner $(1921$, p. 30), da itha de Tenerife, uma variedade de E. communis diferente da espécie típica, entre outros caracteres, pelo tamanho menor; comparei os espécimes atuais com essa forma, excluida por Schuurmans Stekhoven (1935, p. 26) da sinonimia de E. communis. Quanto ao comprimento e à espessura concordam, realmente, os animais do Rio mais com meridionalis que com communis mas, o encurtamento muito forte dos espículos dirigidos para o lado dorsal de meridionalis, como tambêm a largura da peça auxiliar (1. c., t. 2, f. 7) não se reencontram nos exemplares presentes (Fig. 2). O órgão auxiliar pre-anal dos vermes aqui em mãos não pude examinar pormenorizadamente no seu trecho mais interno, mas, ao que parece, não concorda com o órgão correspondente de meridionalis. Visto como não posso reunir as 51 boas espécies mais II duvidosas conhecidas em 1933 do gênero Enoplus (Coninck \& Stekhoven, p, 31-34) devo contentar-me com a classificação genérica, acrescentando que o material concorda em vários caracteres com E. communis. 


\section{Descrição da anomalia}

A anomalia do verme consiste no seguinte: apesar de ser uma fêmea (Fig. 3) com todos os orgãos característicos do seu séxo: ovário, útero (contendo 12 ovocitos já bastante grandes e quasi todos em divisão) e vagina (Fig. 4), apresenta, juntamente ao anus, espículos quitínicos semelhantes aos que normalmente existem nos machos em idêntica posição. Os espículos da fêmea anormal são um pouco mais compridos que os dos machos normais. Um dos espículos é levemente mais comprido que o outro, achando-se ambos parcialmente protraidos. Ao lado desse par existem duas peças accessórias ("gubernacula") grossas e curtas, que apresentam estriação transversal. Próximo ao orifício anal ocorre corpúsculo esférico, evidentemente tambêm quitinoide (Fig. 5). Tal "globular body" foi igualmente encontrado por Steiner (1923, p. 152 f. 8, sp4) e considerado por êle como espículo supernumerário, unilateralmente desenvolvido. Numa das outras fêmeas do material presente existe corpúsculo esférico semelhante. Esse espículo rudimentar constitue na dita fêmea o único representante dos elementos copulatórios masculinos.

\section{Anomalias sexuais em outros Nematodes}

Conhecem-se vários casos em que fenômenos do tipo descrito ocorrem nos Nemátodes. De Man (1893, p. 99, III) observou numa fêmea de Chromadora poecilosoma e em outra de Thoracostoma figuratum a presença do aparelho copulatório masculino completo e em nada distinguivel do sistema correspondente de machos normais. $O$ mesmo autor (1904, p. 24), relata ainda achado de três fêmeas de Enoplus $\mathrm{michaelseni}$ que apresentam espículos copulatórios, peças accessórias, papilas e cerdas, do tipo masculino. Em nenhuma destas três fêmeas, que aliás diferiam entre $s i$, os caracteres sexuais secundários masculinos eram completamente desenvolvidos. Além disso o autor diz ter encontrado "muito raramente" tal anormalidade entre os Nemátodes marinhos de vida livre, "habitat" em que vivem as três espécies mencionadas. Stekhoven e Adams (193I, p. II) encontraram no meio de muitos indivíduos de outra espécie marinha, Anticoma limalis uma única fêmea com espículos rudimentares e, por isso, chamada de intersexuada. Conhece-se tambêm do gênero Halichoanolaimus uma fêmea intersexuada (Schuurmans Stekhoven 1935, p. 70: H. microspiculum. Allgén 1929).

Em outros Nemátodes límnicos, foram observados indivíduos intersexuados em várias espécies do gênero Trilobus lem T. I ongus por 
v. Daday 1905; em T. gracilis por Ditlevsen 1911, p. 233; Schneider 1925, p. 546, e outros autores). Tanto Hagmeier (1912) como Steiner estudaram nos gêneros Mermis, Agamermis e Paramermis numerosos intersexuados (Hagmeier chama-os de hermafroditas). Com as citações aqui compiladas não pretendo registrar todas as observações relativas a fêmeas de Nemátodes com elementos morfológicos masculinos, mas, apenas mencionar alguns dos casos mais conhecidos. Em todas as observações de indivíduos intersexuados trata-se sempre de fêmeas que possuem todos os caracteres sexuais femininos, primários e secundários perfeitamente desenvolvidos. O gráo de desenvolvimento dos caracteres sexuais masculinos varia, sendo estes completos em um espécime, apenas esboçados no outro. Das publicações citadas depreende-se, além disso, que varia muito, nas várias espécies, o número de intersexuados, em relação com o número total dos indivíduos da população examinada. Nos gêneros Mermis, Agamer$m$ is e Paramermis, o número de intersexuados é igual ou até maior que o das fêmeas normais (Steiner, 1923, p. 159); ao passo que de Man (1904, p. 24) observou o fenômeno nas espécies marinhas, muito raramente.

Desde que Meissner em 1854 (p. 209, 257-259) descreveu com tanto cuidado o fenômeno em Agamermis albicans encontram-se frequentemente na literatura referências correspondentes a outras espécies dágua doce. Por outro lado são escassas as notas correspondentes sobre as espécies marinhas da vida livre. No gênero Trilobus, límnico, a ocorrência de intersexuados é muito comum. Esse gênero foi bem estudado a respeito da variabilidade morfológica dentro da espécie (Stefanski 1917). evidenciando-se a existência de grande número de raças diferentes. Cresce em tais espécies a probabilidade da ocorrência de vários genotipos entrelaçados, à semelhança dos estudados por Johanssen no feijão. E'verdade que Micoletzky (1917. p. 508) duvida do valor das raças como verdadeiramente existentes. Todavia assemelham-se as curvas de variabilidade de Tril obus gracilis, dadas por Micoletzky (1917. t. 19 f. 2a-e, t. 20 f. 3a-f), muito às de Johanssen. A importância genética dessas raças ou grupos morfológicos não poderá ser resolvida enquanto não fôr criado o Nemátode em questão.

Tão pouco quão em Trilobus foi provada, por meio de cruzamentos. adequados, intersexualidade verdadeira dos Nemátodes nos outros acima mencionados (Steiner, 1923 p. 147). 


\section{Discussão das anomalias sexuais dos Nematodes}

Conhecem-se dois tipos fundamentais de anormalidade sexual, a intersexualidade e o ginandromorfismo. A primeira é condicionada, principalmente, pelo cruzamento de raças diferentes, causa de novas combinações genotípicas [Goldschmidt). Admite-se nessas recombinações alteração do equilíbrio entre os gens, possivelmente os determinantes do sexo. Tal desequilíbrio considera-se a causa da formação de intersexuados. Cruzamentos diferentes dão origem a animais com gráos diferentes de intersexualidade; desde machos e fêmeas com ligeiros traços do outro sexo, até indivíduos com completa inversão sexual.

O ginandromorfismo deve-se, muitas vezes, a irregularidades mitóticas que causam a perda de um cromosoma sexual. As zonas do corpo do animal adulto que derivam das células empobrecidas quanto ao número de cromosomas, apresentam os caracteres do outro sexo, se $\circ$ animal, em que tal divisão anomala ocorreu, era homozigoto. Contam-se entre eles os hermafroditas bilaterais e os ginandromorfos, cujo corpo possue regiōes asimétricas masculinas e femininas. $O$ indivíduo intersexuado apresenta-se como gráo intermediario entre macho e fêmea; o ginandromorfo é um mosaico de parte masculinas e femininas.

Segundo Steiner $(1923$, p. 155) deve-se o grande número de intersexuados na espécie Agamermis decaudata à hibridação de vários genotipos, citando Goldschmidt (1927, p. 608-611) e Dreyfus (1937. p. 100-101) e outros, esses exemplares de Agamermis entre os exemplos de intersexualidade diploide. De fato existem nes̀se gênero várias raças diferentes como tambêm vários gráos de intersexualidade sem alteração paralela de todos os orgãos implicados na transformação. Uns são muito modificados, outros, no mesmo animal, não tanto (Steiner 1923, p. 158; Goldschmidt 1931, p. 137: Lymantria dispar). Em Trilobus longus T. diversi-pa pillatus Dad.) v. Daday encontrou (1905, citado seg. Steiner 1923. p. 157) uma fêmea fortemente intersexuada. Além de apresentar aparelho copulador e demais caracteres sexuais secundários masculinos perfeitos e normais, possuia pequeno testículo com curto duto ejaculatório, evidentemente sem função. Caso semelhante foi descrito por Micoletzky (1917, p. 509) em Trilobus gracilis. Essas observações apoiam a opinião geral (Rauther, 1930, p. 319; Meisenheimer 1930, p. 254) de que se trate de verdadeira intersexualidade nos casos de anormalidade sexual nos Nemátodes, provavelmente oriunda de cruzam ıntos de raças diferentes (Meisenheimer 1930. D. 207-2081. 
Por outro lado não se pode excluir a hipótese do ginandromorfismo, favorecida até pela inexistência de machos sexualmente anômalos. Existe, porém, em analogia ao que foi observado em $L$ y $m$ a $n t r i a_{1}$ possibilidade de explicar como intersexualidade o fenômeno, apesar de se restringir às fêmeas. Se admitirmos um fator feminilizante forte $(F)$ em todas as raças, formar-se-iam machos apenas quando a combinação gênica respetiva fosse isenta de tal fator. Sempre que ocorresse o fator $F$ haveria o aparecimento de fêmeas normais. Quanto aos fatores masculinizantes (M), poderia haver fortes e fracos como no caso de Lymantria. Quando, devido a uma combinação qualquer, se reunissem numa fêmea (portadora de um fator $F$ ). um ou dois fatores $M$ suficientemente fortes para contrabalançarem a ação de $F$, essa fêmea tornar-se-ia intersexuada. O grande número de intersexuados em Agamermis não está em desacordo com esta hipótese, visto como, com cruzamentos apropriados, obteve Goldschmidt intersexualidade em $100 \%$ das fêmeas prospetivas. Combinando essa adatação dos achados de Goldschmidt aos Nemátodes límnicos onde são numerosos os casos de anormalidade sexual, a restrição do fênomeno às fêmeas não impediria a sua interpretação como intersexualidade. Em espécies marinhas, onde a ocorrência da anormalidade sexual é rara, mas sempre encontrada em fêmeas, parece possivel tratar-se de ginandromorfismo. Em Chromadora e Thoracostoma analisados por De Man (1893) e no caso de um dos Enoplus aqui presente, o aparelho copulador masculino é completo. No espécime de Anticoma relatado por Stekhoven e Adams e nas três fêmeas de Enoplus estudadas por de Man (1904), o aparelho genital masculino é incompletamente desenvolvido. Nesse último caso pode-se admitir a perda do respetivo cromosoma num estadio já adiantado do desenvolvimento.

Possivelmente não são todos os casos de anormalidade sexual nos $\mathrm{Ne}$ mátodes devidos a fenômenos da mesma ordem. Nas espécies terrestres e límnicas, com fêmeas anormais frequentemente ocorrentes e tendência para a formação de raças diferentes é muito provavel tratar-se de intersekualidade verdadeira; nas espécies marinhas cujas fêmeas apenas às vezes são sexualmente anormais é possivel a existência de ginandromorfismo.

\section{Summary}

Among some free-living Nematodes (gen. Enoplus) from Rio de Janeiro (3 females, 3 males) one of the females was sexually anormal. Sistematically the present material is similar to Enoplus communis but considerably smaller: E. communis var. meridionalis Steiner has different spi- 
cules E. hirtus is bigger than the specimes from Rio and E. minor has different body formula. The character of the anormal female consist in the presence of spicules and gubernacula only slightly different from those of the normal males. The record of anterior description of similar anormalities shows that such cases only occur in females and are much more rare in marine than in limnic species, where they are frequent (Tri lobus. Mer$m i s$, Agamermis, Paramermis). Attempting to explain the inexistence of anormalous males the author admits a strong female factor and all types of strong and weak male factores in all races. Certain combinations can produce males if the female factor is absent. Intersexual females would result if in the same combination a strong female and a strong male factor meet. In marine species the phenomenon might be due to gynandromorphism as well as to intersexuality, for the limnic ones the opinion generally adopted that the abnormal females are intersexes, seems to be the only admissible.

\section{Bibliografia}

BOTSCHLI, O. 1874, Zur Kenntnis der freilebenden Nematoden, etc. Abh. Senckenb. naturf. Ges. v. 9, p. I-56, t. I-9. Frankfurt a. M.

CONINCK, L. A. DE \& SCHUURMANS STEKHOVEN, JR. J. H. 1933, The Freeliving Marine Nemas of the Belgian Coast II. Mém. Mus. Roy. Hist. Nat. Belg. mém. n. 58, p. 1-163. Bruxelles.

DITLEVSEN, H. 1911, Danish Freeliving Nematodes. Vidensk. Meddel: Dansk Naturh. Foren. v. 63, p. 213-256 t. 1-5. Köbenhavn.

DREYFUS, A. 1937, Contribuição para o estudo do cyclo chromosomico... de Rhabdias fülleborni, etc. Bol. Fac. Fil. Ciênc. Letr. Univers. de S. Paulo 3, Biologia n..$^{0}$. IV + 125 p. 92 f. S. Paulo.

DUJARDIN, J. 1845, Histoire naturelle des Helminthes ou Vers intestinaux. XV +654 +15 p. t. 1-12. Paris.

GOLDSCHMIDT, R. 1927, Die zygofischen sexuellen. Zwischenstufen und die Theorie der Geschlechtbestimmung. Ergebnisse d. Biologie, v. 2, p. 554-684. Berlin.

- 1931. Analysis of Intersexuality in the Gipsy-Moth. Quart. Rev. Biol. v. 6, n. 2, p. 125-142. Baltimore.

HAGMEIER, A. 1912, Beiträge zur Kenntnis der Mermithiden. Zool. Jahrb. Syst. v. 32. fasc. 6, p. 521-6/2 t. 17-21. Jena.

MAN, J. G. DE, 1878, Contribution à la connaissance des Nematoides marins du Golfo de Naples. Tijdschr. Nederl. Dierk. Ver. v. 3, p. 88-118 t. 7-9. Leiden.

- 1893. Cinquième noto sur les Nématodes libres de la Mer du Nord ef de la Manche. Mém. Soc. Zool. France 1893, p. 81-125 t. 5-6. Paris.

- 1904, Nématodes libres. Rés. Voy. Belgica. 51 p. II. t. Anvers.

MARION, A. F. 1870, Recherches zoologiques et anatomiques sur des Nématoídes non parasites, marins. Ann. Sci. nat. (Zool.) v. 13 art. 14, p. 1-100 t. 3-14 (paginação da separatal. Paris. 
MEISENHEIMER, J. 1930, Geschlecht und Geshlechter im Tierreich. v. 2, IV +614 p. 219 f. Jena (G. Fischer).

MEISSNER, G. 1854, Beiträge zur Anatomie und Physiologie von Mermis albicans. Zeitschr. Wissensch. Zool. v. 5, p. 207-284 t. 11-15. Leipzig.

MICOLETZKY, H. 1917, Freilebende Suesswasser-Nematoden der Bukowina. Zool. Jahrb. Syst. v. 40, p. 441-586 t. 19-22. Jena.

- 1924, Weitere Beiträge zur Kenntnis freilebender Nematoden aus Suez. S. Ber. Akad. wissensch. Wien. Mathem. Naturw. Klasse ser. I v. 132 n.: 7-8 (1923), p. 225-262. Wien.

RAUTHER, M. 1930, Nematodes. Kuekenthal \& Krumbach. Handb. d. Zoologie, v. 2. I." metade (Vermes Amera), p. 249-402 f. 267-426. Berlin \& Leipzig (Walter de Gruyter).

SCHNEIDER, W. 1925, Freilebende Suesswassernematoden aus Ostholsteinischen Seen. Arch. Hydrobiol. v. 15 p. 536-584. Stuttgart.

- 1939. Freilebende und pflanzenparasitische Nematoden. M. Dahl \& H. Bischoff. Tierwelt Deutschlands pars 36, 260 p. 455 f. Jena (G. Fischer).

SCHUURMANS STEKHOVEN, JR. J. H. \& ADAM, W. 1931. The freeliving Marine Nemas of the Belgian Coast. Mém. Mus. Roy. Hist. Nat. Belg. mém. n. 49, p. I-58 t. 1-10. Bruxelles.

SCHUURMANS STEKHOVEN, JR., J. H. 1935, Nematoda (Systematischer Teil). G. Grimpe, Tierwelt d. Nord \& Ostsee pars $V$ b/c, 173 (b) e 50 (c) p. 412 f. Leipzig (Akadem. Verlagsges.).

STEFANSKI, W. 1917, Sur les races de Trilobus gracilis Bast. Rev. Suisse Zool. v. 25, n. 9 p. 163-168. Genève.

STEINER, W. 1921, Beiträge zur Kenntnis mariner Nematoden. Zool. Jahrb. Syst. v. 32, n. 6. p. 521-612 t. 17-21. Jena.

- 1923, Intersexes in Nematodes. Journ. Hered. v. 14, n. 4, p. 147-158. Washing-ton, D. C. 


\section{ESTAMPA I}

'Fig. 1 - Cabeça da fêmea anormal.

Fig. 2 - Espículos e orgão copulador accessório de macho normal.

Fig. 3 - Fêmea com espículos perto da extremidade caudali ovócitos na fase de maturação.

Fig. 4 - Vulva da fêmea anormal. Ovócitos na fase de maturação.

Fig. 5 - Extremidade caudal da fêmea anormal, com espículos e corpo quitínico globular. 
MARTA VANNUCCI MENDES - Ancmalia sexua!

ESTAMPA

num Nemátode marinho
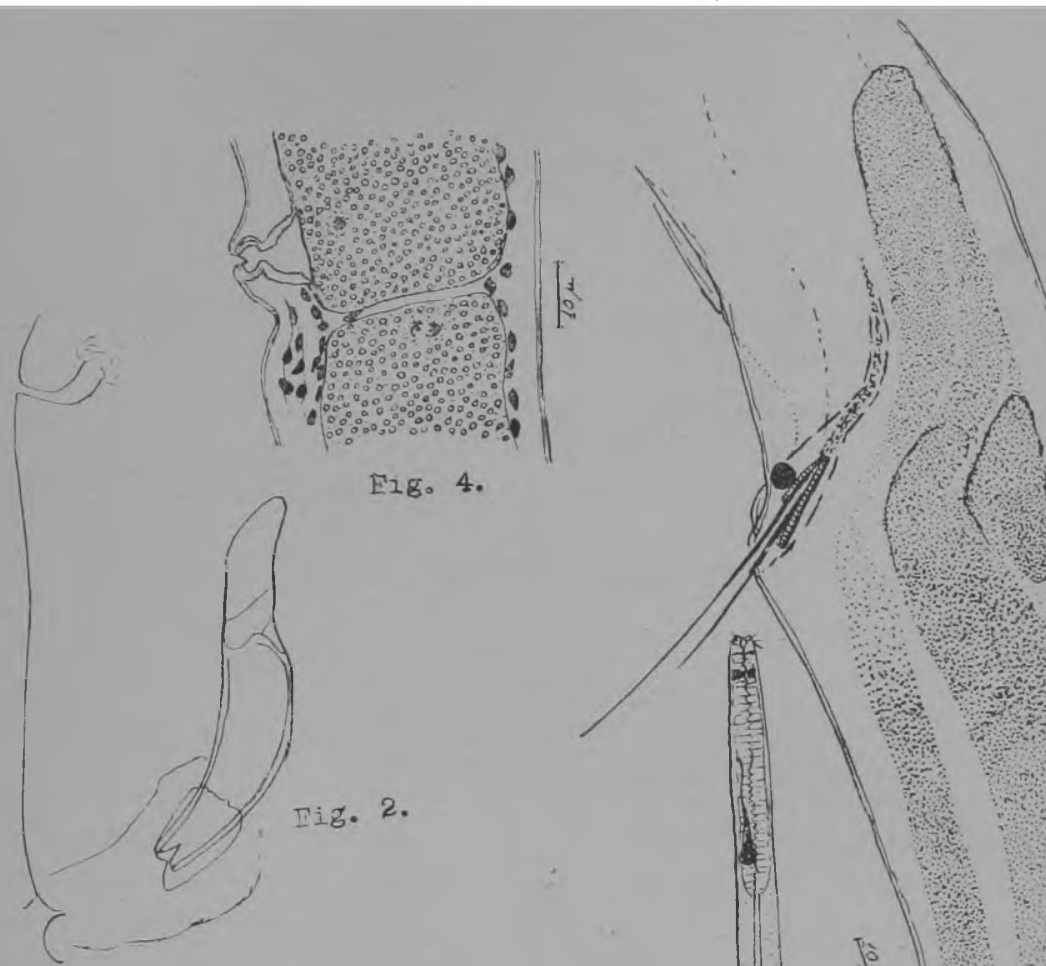